\title{
Effect of abnormal yolk sac, gestational sac and embryonic heart rate in pregnancy outcome
}

\author{
Jyoti Jaiswal $^{1}$, Anand Kumar Jaiswal ${ }^{2}$, Geetanjali Patel ${ }^{1 *}$, Abha Daharwal ${ }^{1}$
}

\begin{abstract}
${ }^{1}$ Department of Obstetrics and Gynecology, ${ }^{2}$ Department of Radiodiagnosis, Pt. JNM Medical College and Dr Bhim Rao Ambedkar Memorial Hospital Raipur, Chhattisgarh, India
\end{abstract}

Received: 28 June 2021

Accepted: 12 July 2021

\author{
*Correspondence: \\ Dr. Geetanjali Patel, \\ E-mail: geet11191@gmail.com
}

Copyright: (C) the author(s), publisher and licensee Medip Academy. This is an open-access article distributed under the terms of the Creative Commons Attribution Non-Commercial License, which permits unrestricted non-commercial use, distribution, and reproduction in any medium, provided the original work is properly cited.

\begin{abstract}
Background: The purpose of the study is to know the effect of abnormal yolk sac, abnormal gestational sac and abnormal embryonic heart rate on outcome of pregnancy in the tertiary care centre of Chhattisgarh.

Methods: This prospective observational study included 50 pregnant females between 6-9 weeks gestation with singleton pregnancy attending antenatal clinic in a tertiary medical institution. Transvaginal sonography was carried out to quantify yolk sac characteristics. Abnormal yolk sac was defined according to Nyberg criteria.

Results: Out of 50 cases, 25 cases had abnormal yolk sac, 23 cases had abnormal gestational sac and 22 cases had abnormal embryonic heart rate and heart rate was absent in 23 cases. Out of 50 cases, 32 got aborted and rest 18 cases had ongoing pregnancy beyond 20 weeks. Normal yolk sac diameter (YSD) (2-5 mm) showed 72.2\% sensitivity, 62.5\% specificity, $52 \%$ positive predictive value and $80 \%$ negative predictive value in predicting pregnancy outcome. Gestational sac diameter had $66.66 \%$ sensitivity, 53.12\% specificity, 44.44\% PPV and $73.91 \%$ NPV and for EHR had $22.22 \%$ sensitivity, $96.87 \%$ specificity, $80 \%$ PPV and $68.88 \%$ NPV.

Conclusions: The embryos with abnormal YSD are highly associated with poor pregnancy outcome with good sensitivity and NPV. Present study indicates that the yolk sac measurement is reliable prognostic factor in predicting $1^{\text {st }}$ trimester pregnancy outcome.
\end{abstract}

Keywords: YSD, Gestational sac diameter, Embryonic heart rate, Transvaginal ultrasonography

\section{INTRODUCTION}

$1^{\text {st }}$ trimester pregnancy is known to be the important period of organogenesis, but could be associated with high complication rate. ${ }^{1,2}$ Spontaneous abortions are one of the important causes of poor pregnancy outcome and prediction of which plays an important role in counseling and management of such pregnancies. So, there is need for a risk assessment model that can predict the risk of early spontaneous abortion.

It is assumed that $30-40 \%$ of early pregnancies in $1^{\text {st }}$ trimester results in spontaneous abortion after implantation. $^{3}$
The first sonographic evidence of pregnancy is the gestational sac within the thickened deciduas. ${ }^{4}$ With TVS (transvaginal sonography), it is possible to identify the sac by 4 weeks and 3 days gestation when the mean diameter is $2-3 \mathrm{~mm} .{ }^{4,5}$ TVS can detects the yolk sac as early as the $5^{\text {th }}$ week of pregnancy. ${ }^{6}$

Normally, the yolk sac appears as a circular structure with an anechoic centre surrounded by a uniform well defined echogenic wall. ${ }^{7}$ It serves as the primary source of materno-fetal transport of nutrients before the placental circulation is fully established. It can be seen beginning at 5.5 weeks reaching its maximum diameter at 10 weeks and then disappears by 12 weeks. $^{8}$ 
Some studies have been done on the prognostic significance of the yolk sac for the pregnancy outcome. But very a smaller number of studies are available in Indian and regional data. The aim of the present study was to evaluate the individual and cumulative effect of yolk sac diameter (YSD), gestational sac diameter and embryonic heart rate and their various characteristics on pregnancy outcome at the end of the first trimester.

\section{METHODS}

This was a prospective observational study, conducted in the Department of Obstetrics and Gynecology, Dr. Bhim Rao Ambedkar memorial hospital Raipur between November 15, 2018 to August 2019 (1 year 4 month) after obtaining clearance from the institutional scientific and ethical committee.

The subjects included 55 pregnant females between 6-9 weeks of gestation, who had either abnormal yolk sac, gestational sac or embryonic heart rate. Exclusion criteria were molar pregnancy, ectopic pregnancy, multiple gestation, structural anomalies of uterus and cervix and pregnancies complicated by endocrine disorders and other associated disorders which can significantly affect the pregnancy outcome.

All the subjects were examined by TVS which was performed by a radiologist. Following parameters were recorded- YSD and its characters, gestational sac diameter and its characters, embryonic heart rate and crown rump length.

YSD was measured by placing the calipers on the inner limits of the longest diameter.

Subjects were asked for a follow up visits at the end of $13^{\text {th }}$ week. On follow up visit repeat abdominal sonography was performed. Normal outcome was defined as continuation of pregnancy beyond 20 weeks of gestation with intact gestation sac and a live fetus in utero confirmed sonographically. Abnormal outcome was defined as abortion occurring before 20 weeks or non-viable pregnancy on follow-up scan at 13 weeks.

Descriptive statistical analysis was carried out in this study. Results on continuous measurements are presented on Mean, SD and results on categorical measurements are presented in numbers (\%). Chi-square test was used to find the significance of study parameters on categorical scale between two or more groups. $\mathrm{P}<0.005$ was considered to be statistically significant.

\section{RESULTS}

Total 55 pregnant females were included in the present study. The 5 subjects were lost to follow up. Finally, 50 subjects were included into the study. The outcome of the study was evaluated in terms of miscarriage or normal continuation of pregnancy at the end of $20^{\text {th }}$ week.
Table 1 demonstrates the descriptive data of the various parameters recorded in 50 subjects along with mean \pm SD.

Socio-demographic profile of this study demonstrates that majority of the cases $(96 \%)$ were more than 20 years of age with mean age group of 26.4 years. $60 \%$ of the cases belongs to urban area and rest $40 \%$ belongs to rural area. Cases were equally distributed among APL and BPL group. Among 50 study population, $21(42 \%)$ were primigravidae and 29 (58\%) were multi-gravidae.

Effect of demographic variables like maternal age, geography, education and socio-economic status, on pregnancy outcome were not significant statistically. There was no statistically significant difference found in miscarriage rates with regard to gravidity of the patient.

Table 2 shows that smaller and larger yolk sac were associated more with abortion as compared to normal YSD. Outcome of pregnancy was favorable when YSD ranged between $2-5 \mathrm{~mm}$. Survival rate were 52\% (13/25), when YSD was between $2-5 \mathrm{~mm}$. Survival rate was $30 \%$ $(3 / 10)$ and $18.18 \%(2 / 11)$ when YSD was $>5 \mathrm{~mm}$ and $<2$ $\mathrm{mm}$ respectively (Figure 1 ).

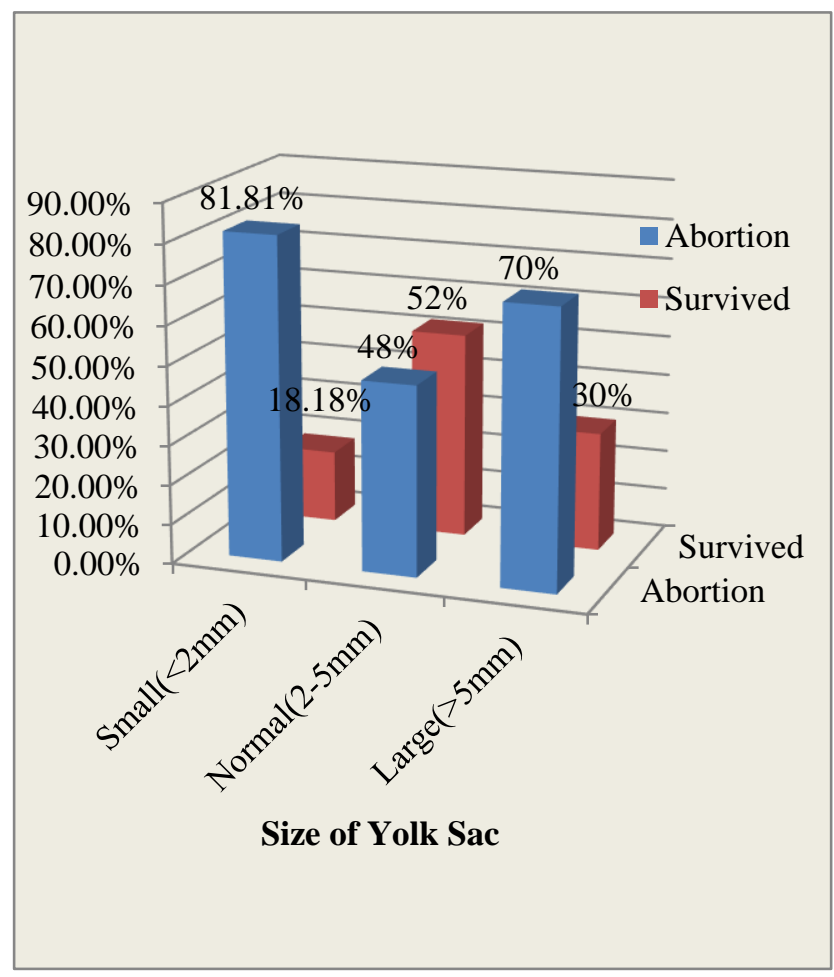

Figure 1: Outcome of pregnancy based on yolk sac size.

Table 3 shows that if the appearance of yolk sac is abnormal, there was high chance of abortion (90.47\%, 19/21), but normal appearance does not conclude for high chance of survival.

Nyberg criteria was used to describe the appearance of yolk sac. ${ }^{9}$ 
Major criteria were-A large sac $(\geq 25 \mathrm{~mm}$ mean sac diameter without embryo OR, $\geq 20 \mathrm{~mm}$ mean sac diameter without a yolk sac), distorted shape of the gestational sac.

Minor criteria included-Thin decidual reaction less than 2 $\mathrm{mm}$, irregular contour of gestational sac, absent double decidual sign, weak decidual amplitude and low position of the sac.

Findings were abnormal if any 1 major criteria or any 3 minor criteria were present.

Out of 50 subjects, 23 cases had abnormal gestational sac diameter. Out of 23 cases $73.91 \%$ (17/23) got aborted.

Table 4 shows that abnormal gestational sac diameter was associated with higher abortion rate, although difference was not statistically significant.

In present study, 7 cases had irregular gestational sacs, out of which 3 cases had normal gestational sac diameter, but only 1 case (14.28\%) survived, while rest 6 cases $(85.71 \%)$ got aborted.

Out of 50 cases heart rate was absent in 23 cases, and present in 27 cases. Among 27 cases heart rate was $<100$ bpm in 13 cases, $>180$ bpm in 9 cases while normal in only 5 cases. Abortion rate was maximum i.e.,53.85\% with EHR $<100 \mathrm{bpm}$ followed by $20.0 \%$ with $100-180 \mathrm{bpm}$ and $11.11 \%$ with EHR >180 (Figure 2).

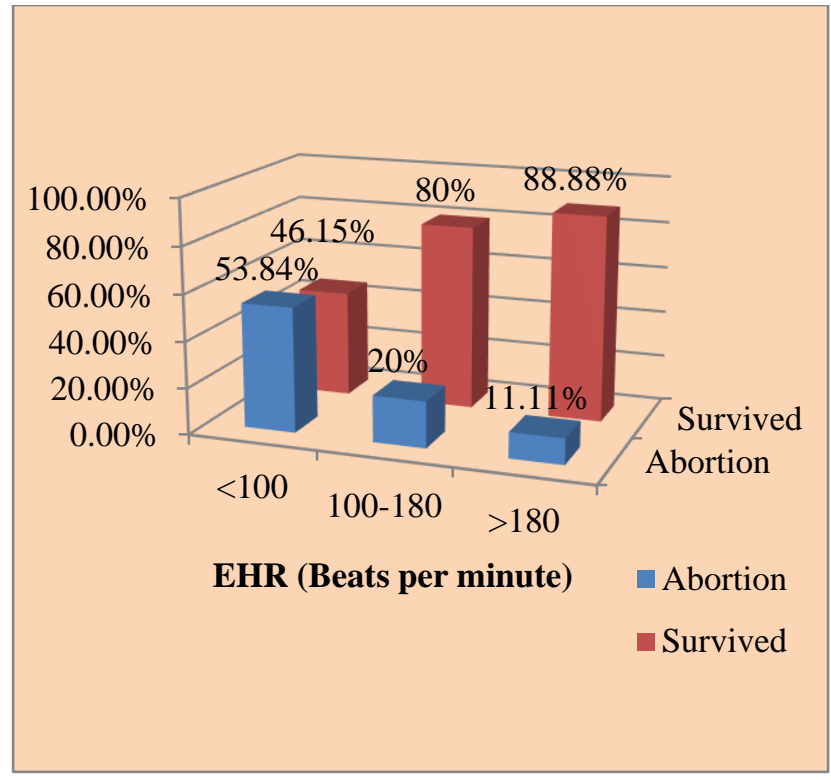

Figure 2: Outcome of pregnancy based on EHR.

When all the 3 parameters were abnormal then it leads to abortion in $100 \%$ of the cases. When isolated YSD was abnormal, chance of abortion was high as compared to isolated GSD and EHR abnormality (Table 5).

Table 6 shows that YSD has maximum sensitivity and NPV while EHR has maximum specificity and PPV.

Table 1: Descriptive data of all parameters.

\begin{tabular}{|lllll|}
\hline Data & Minimum & Maximum & Mean & SD \\
\hline Age (years) & 18 & 35 & 26.4 & 3.927 \\
\hline Gestational sac size (mm) & 2.43 & 56 & 27.26 & 13.27 \\
\hline Yolk sac size (mm) & 1.5 & 20.8 & 3.789 & 3.40 \\
\hline Embryonic heart rate (bpm) & 58 & 200 & 68.52 & 51.34 \\
\hline Gestational age (weeks) & 6 & 9 & $7.5 w \mathrm{k}$ & 6.839 \\
\hline Crown rump length $(\mathbf{m m})$ & 2.0 & 25.4 & 9.49 & 6.43 \\
\hline
\end{tabular}

Table 2: Distribution and outcome of pregnancy based on size of the yolk sac.

\begin{tabular}{|c|c|c|c|c|c|c|c|}
\hline \multirow{3}{*}{ YSD } & \multicolumn{4}{|c|}{ Pregnancy } & \multirow{2}{*}{\multicolumn{2}{|c|}{ Total }} & \multirow{2}{*}{ Statistical inference } \\
\hline & \multicolumn{2}{|c|}{ Abortion } & \multicolumn{2}{|c|}{ Survived } & & & \\
\hline & No. & $\%$ & No. & $\%$ & No. & $\%$ & \\
\hline Small (<2 mm) & 9 & 81.81 & 2 & 18.18 & 11 & 23.91 & The chi-square statistic is \\
\hline Normal (2-5 mm) & 12 & 48 & 13 & 52 & 25 & 54.34 & 5.5556. The $\mathrm{p}=0.018422$ \\
\hline Large (>5 mm) & 7 & 70 & 3 & 30 & 10 & 21.73 & Significant at $\mathrm{p}<0.05$. \\
\hline Total & 28 & 60.86 & 18 & 39.13 & 46 & 100 & \\
\hline
\end{tabular}

Table 3: Distribution and outcome of pregnancy based on appearance of yolk sac.

\begin{tabular}{|c|c|c|c|c|c|c|c|}
\hline \multirow{3}{*}{$\begin{array}{l}\text { Appearance of } \\
\text { yolk sac }\end{array}$} & \multicolumn{4}{|c|}{ Pregnancy } & \multirow{2}{*}{\multicolumn{2}{|c|}{ Total }} & \multirow{2}{*}{ Statistical inference } \\
\hline & \multicolumn{2}{|c|}{ Abortion } & \multicolumn{2}{|c|}{ Survived } & & & \\
\hline & No. & $\%$ & No. & $\%$ & No. & $\%$ & The Chi-square statistics is \\
\hline Abnormal & 19 & 90.47 & 2 & 9.52 & 21 & 42 & 11.0159. The $\mathrm{p}=0.000903$. \\
\hline Normal & 13 & 44.82 & 16 & 55.17 & 29 & 56 & The results are significant at \\
\hline Total & 32 & 64 & 18 & 36 & 50 & 100 & $\mathrm{p}<0.05$ \\
\hline
\end{tabular}


Table 4: Distribution and effect of gestational sac diameter on outcome of pregnancy.

\begin{tabular}{|c|c|c|c|c|c|c|c|}
\hline \multirow{3}{*}{$\begin{array}{l}\text { Gestational sac } \\
\text { diameter }\end{array}$} & \multicolumn{4}{|c|}{ Pregnancy } & \multirow{2}{*}{\multicolumn{2}{|c|}{ Total }} & \multirow{2}{*}{ Statistical inference } \\
\hline & \multicolumn{2}{|c|}{ Abortion } & \multicolumn{2}{|c|}{ Survived } & & & \\
\hline & No. & $\%$ & No. & $\%$ & No. & $\%$ & The chi-square statistics is \\
\hline Abnormal & 17 & 73.91 & 6 & 26.08 & 23 & 46 & 1.8166. The $p=0.177715$. The \\
\hline Normal & 15 & 55.55 & 12 & 44.44 & 27 & 54 & result is not significant at \\
\hline Total & 32 & 64 & 18 & 36 & 50 & 100 & $\mathrm{p}<0.05$ \\
\hline
\end{tabular}

Table 5: Individual as well as cumulative effect of YSD, GSD and EHR on pregnancy outcome.

\begin{tabular}{|c|c|c|c|c|c|c|}
\hline \multirow{2}{*}{ Abnormal parameters } & \multicolumn{2}{|c|}{ Abortion } & \multicolumn{2}{|c|}{ Survived } & \multicolumn{2}{|c|}{ Total } \\
\hline & No. & $\%$ & No. & $\%$ & No. & $\%$ \\
\hline All 3 parameters (YSD, GSD and EHR) $(n=9)$ & 9 & 100 & 0 & 0 & 9 & 100 \\
\hline \multicolumn{7}{|l|}{ Any two parameters abnormal } \\
\hline YSD and GSD $(n=1)$ & 0 & 0 & 1 & 100 & 1 & 3.33 \\
\hline YSD and HER $(n=15)$ & 11 & 73.33 & 4 & 26.66 & 15 & 50 \\
\hline GSD and HER (n=14) & 11 & 78.57 & 3 & 21.42 & 14 & 46.66 \\
\hline \multicolumn{7}{|l|}{ Any one abnormal parameter } \\
\hline YSD $(n=1)$ & 1 & 100 & 0 & 0 & 1 & 9.09 \\
\hline GSD $(n=3)$ & 0 & 0 & 3 & 100 & 3 & 27.27 \\
\hline HER $(n=7)$ & 0 & 0 & 7 & 100 & 7 & 63.63 \\
\hline
\end{tabular}

Table 6: Diagnostic test parameters for normal YSD, normal gestational sac diameter and normal EHR.

\begin{tabular}{|llll|}
\hline Test parameters & YSD $(\mathbf{2}-\mathbf{5} \mathbf{~ m m})(\boldsymbol{\%})$ & $\begin{array}{l}\text { Gestational sac } \\
\text { diameter }(\%)\end{array}$ & $\begin{array}{l}\text { Embryonic heart rate } \\
(\mathbf{1 0 0}-\mathbf{1 8 0} \text { bpm) }(\%)\end{array}$ \\
\hline Sensitivity & 72.22 & 66.66 & 22.22 \\
\hline Specificity & 62.5 & 53.12 & 96.87 \\
\hline Positive predictive value (PPV) & 52 & 44.44 & 80 \\
\hline Negative predictive value (NPV) & 80 & 73.91 & 68.88 \\
\hline
\end{tabular}

\section{DISCUSSION}

An increased risk of pregnancy failure was seen to be associated with abnormality in YSD, gestational sac diameter (GSD), and EHR. Various studies have been done till now to evaluate the one or two USG parameters. But in present study, all the 3 parameters of viability of fetus i.e., yolk sac, gestational sac and EHR is taken together.

In present study patient varied from 18-35 years of the age with majority of the cases between 21-30 years of age with mean age of $26.4 \pm 3.92$ years.

Demographic variables were noted like geographical distribution, education, socio-economic status and age. It was found that these variables do not significantly affect the pregnancy outcome.

Out of 50 cases, 21 were primigravidae and 29 were multigravidae. $52.38 \%(11 / 21)$ of primigravidae and $72.41 \%$ $(21 / 29)$ of multi-gravidae got aborted. Gravidity did not significantly affect the pregnancy outcome but increase in abortion rates was observed with increasing gravidity. Similar results were observed in studies performed by Adiga et al and Manchanda et al. ${ }^{3,10}$ However Makrydimas et al seems to agree with the negative impact of maternal age and history of miscarriage to subsequent pregnancy. ${ }^{11}$

In present study, yolk sac with diameter $<2 \mathrm{~mm}$ was categorized as small, 2-5 $\mathrm{mm}$ as normal and $>5 \mathrm{~mm}$ as large yolk sac. It was observed that when the mean YSD was 2$5 \mathrm{~mm}$, survival rate was $52.0 \%(13 / 25)$. However, when the YSD fell outside of this range, survival rate was significantly decreased (for $<2 \mathrm{~mm}-18.18 \%, 2 / 11$ and for $>5 \mathrm{~mm}-30.0 \%, 3 / 10)$. Similar results were observed in study performed by Bae and Karnitis in 2011 and Adiga et al in $2015 .^{3,12}$

It was observed that subjects with smaller YSD had higher miscarriage rate $(<2 \mathrm{~mm}, 81.81 \%, 9 / 11)$ as compared to the subjects with larger YSD (>5 mm, 70.0\%, 7/10) reflecting that patient with smaller YSD needs to be counseled and monitored more carefully on further follow up scan.

When normal size of yolk sac is present, pregnancy outcome may vary according to other associated factors.

In present study, 29 patients had normal appearing yolk sacs and of them $55.17 \%(16 / 29)$ had ongoing pregnancy and remaining $44.82 \%(13 / 29)$ aborted. Whereas those 
with abnormal appearing yolk sac, only $11.76 \%(2 / 17)$ had ongoing pregnancy and $88.23 \%(15 / 17)$ got aborted. It was observed that with abnormal appearance of yolk sac in size, shape or number, rate of miscarriage increased significantly. Studies conducted by Kucuk et al, Moraden et al and present study shows significant correlation between abnormal appearance of yolk sac and rate of miscarriage while opposing results were observed in study conducted by Tan et al. ${ }^{13-15}$

The first reliable gray scale evidence of an intra-uterine pregnancy is visualization of the gestational sac within the thickened decidua. In present study out of 50 cases, 23 had abnormal gestational sac diameter while rest 27 cases had normal GSD. Among 23 cases, 13 gestational sacs (26\%) were large in size, whereas only $10(20 \%)$ were smaller in size. Out of these 23 cases with abnormal gestational sac diameter, $73.91 \%(17 / 23)$ aborted, while $26.08 \%(6 / 23)$ patients had ongoing pregnancy.

There were 7 patients who had irregular gestational sac, out of which 3 cases had normal GSD, but only 1 case continued, rest aborted $(6 / 7,85.7 \%)$.

When GSD was abnormal, chance of survival was $26.08 \%$, while with abnormal appearing gestational sac, it was only $14.28 \%$. It indicates that for gestational sac, its appearance is more reliable predictor of pregnancy outcome than its diameter.

Studies conducted by Bromley et al and Falco et al observed that a smaller than expected gestational sac can be a predictor of poor pregnancy outcome, alone or in combination with other parameters. ${ }^{16,17}$ While study by $\mathrm{Oh}$ et al showed that in very early pregnancy ( $<5$ weeks $)$ GSD plays no role in determining pregnancy outcome, the difference becomes apparently after 5 weeks. ${ }^{18}$ So, GSD measurements could not be considered as good predictor of $1^{\text {st }}$ trimester outcome due to wide scatter in gestational sac measurements in normal early pregnancy.

It was observed that slow EHR serves as an indicator of poor pregnancy outcome. During early gestation, the slower EHR could be due to immaturity of the sinoatrial node or the atrial pacemaker may actually be slower. ${ }^{19}$ The mechanism of fetal bradycardia is still unclear but may represent idioventricular rates of the abnormal heart. ${ }^{20}$

Present study reported pregnancy loss in 1 patient $(1 / 5$, 20\%) who had normal EHR. 7 abortions occurred when HR was <100 bpm (7/13, 53.84\%), whereas only 1 abortion occurred when HR was $>180 \mathrm{bpm}(2 / 9,11.11 \%)$. A significant correlation is observed in present study and study conducted by Benson and Doubilet et al, and Adiga et al. ${ }^{21,3}$

When EHR was abnormal along with the abnormality of YSD then chances of survival were only $26.66 \%$, and with abnormality of GSD it was $27.27 \%$ while isolated EHR abnormality ( $<100 \mathrm{bpm}$ or $>180 \mathrm{bpm}$ ) were not associated with the adverse pregnancy outcome. As abnormality of EHR is the mode of loss of viability, we can't say with surely that whether abnormal EHR is cause of abortion or the effect of abnormal yolk sac and gestational sac.

Table 6 shows that YSD has maximum sensitivity $(72.22 \%)$ and NPV (80.0\%). As it has good NPV, absence of abnormal YSD will exclude much chances of early pregnancy loss and will result in a good rate of continuation of pregnancy.

Value of all the parameters i.e., sensitivity, specificity, PPV and NPV are for gestational sac are less as compared to yolk sac. Although NPV can be used for prediction of outcome of pregnancy in early trimester.

EHR has very high specificity and good PPV but the drawback is that it has very low sensitivity and NPV is also low as compared to YSD and GSD.

\section{CONCLUSION}

YSD and its characteristics correlate significantly with the $1^{\text {st }}$ trimester pregnancy outcome. Abnormal YSD is highly associated with poor pregnancy outcome with good sensitivity and negative predictive value. When YSD was abnormal then chances of abortion remain high, furthermore smaller YSD is having higher abortion rate as compared to the large YSD. Abnormal appearance of the yolk sac also was associated with high abortion rate. Thus, the present study indicates that the yolk sac measurement is reliable prognostic factor in predicting $1^{\text {st }}$ trimester pregnancy outcome.

Combined prediction of early pregnancy loss with yolk sac abnormality along with other parameters like gestational sac and EHR gives almost $100 \%$ prediction.

For finding out the further correlation between outcome and characteristics of yolk sac, larger cohort is required for better prediction.

Funding: No funding sources

Conflict of interest: None declared

Ethical approval: The study was approved by the Institutional Ethics Committee

\section{REFERENCES}

1. Celen S, Dover N, Seckin B, Goker U, Yenicesu O, Danisman N. Utility of First Trimester Ultrasonography before 11 Weeks of Gestation: a retrospective Study. Obstet and Gynecol. 2012;2012:6.

2. Morin L, Hof V. Ultrasound evaluation of first trimester pregnancy complications. J Obstet and Gynaecol. 2005;27(6):581-91.

3. Adiga P, Selvi C, Rai L, Hebbar S. Evaluation of yolk sac diameter and embryonic heart rate as prognostic 
factors of gestational outcome in early singleton pregnancies. Sch J App Med Sci. 2015;3(2A):543-50.

4. Goldstein SR. Early detection of pathologic pregnancy by transvaginal sonography. J Clin Ultrasound. 1990 May;18(4):262-73.

5. Timor-Tritsch IE, Farine D, Rosen MG. A close look at early embryonic developmentwith the highfrequency transvaginal transducer. Am J ObstetGynecol. 1988;159(3):676-81.

6. Makikallio K, Tekay A, Jouppila P. Yolk sac and umbilico-placental hemo-dynamics during early human embryonic development. Ultrasound Obstet Gynecol. 1999;14(3):175-9.

7. Levi CS, Dashefsky SM, Lyons EA, Holt CS, Lindsay DJ. First-trimester ultrasound. In: McGahan JP, Goldberg BB, editors. Diagnostic Ultrasound: A Logical Approach. $1^{\text {st }}$ ed. Philadelphia, PA: Lippincott-Raven. 1997:134-48.

8. Srivastava G, Nagwani M, Pasricha N, Tewari V, Siddiqui M, Sthapak E. Sizeof yolk sac by ultrasonography and its correlation with pregnancy outcome. Int J Anat Res. 2016;4(1):2052-7.

9. Nyberg DA, Laing FC, Filly RA. Threatened abortion: sonographic distinction of normal and abnormal gestation sacs. Radiology. 1986;158(2):397-400.

10. Manchanda P, Birla N, Dharamdasani M, Shetty N. Correlation of yolk sac diameter on TVS with fetal outcome. Int J Sci Res. 2016;5(4):1022-4.

11. Makrydimas G, Sebire NJ, Lolis D, Vlassis N, Nicolaides KH. Fetal loss following ultrasound diagnosis of a live fetus at 6-10 weeks of gestation. Ultrasound Obstet Gynaecol. 2003;22(4):368-72.

12. Bae S, Karnitis J. Triple ultrasound markers including fetal cardiac activity are related to miscarriage risk. Fertil Steril. 2011;96(5):1145-8.
13. Kucuk T, Duru NK, Yenen MC, Dede M, Ergun A, Baser I. Yolk sac size and shape as predictors of poor pregnancy outcome. J Perinat Med. 1999;27(4):31620.

14. Moradan S, Forouzeshfar M. Are Abnormal Yolk Sac Characteristics Important Factors in Abortion Rates? Int J Fertil Steril. 2012;6(2):127-30.

15. Tan S, İpek A, Pektas MK, Arifoğlu M, Teber MA, Karaoğlanoğlu M. Irregular Yolk Sac Shape. J Ultrasound Med. 2011;30(1):31-6.

16. Bromley B, Harlow BL, Laboda LA, Benacerraf BR. Small sac size in the first trimester: a predictor of poor fetal outcome. Radiology. 1991;178(2):375-7.

17. Falco P, Zagonari S, Gabrielli S, Bevini M, Pilu G, Bovicelli L. Sonography of pregnancies with firsttrimester bleeding and a small intrauterine gestational sac without a demonstrable embryo. Ultrasound Obstet Gynecol. 2003;21(1):62-5.

18. OhJ S, Wright G, Coulam CB. Gestational sac diameter in very early pregnancy as a predictor of fetal outcome. Ultrasound Obstet Gynecol. 2002;20(3):267-9.

19. Shenker L, Astke C, Reed K, Anderson C. Embryonic heart rates before the seventh week of pregnancy. J Reprod Med. 1986;31(5):333-5.

20. Laboda LA, Eastroff JA, Benacerraf BR. First trimester bradycardia: A sign of impending foetal loss. J Ultrasound Med. 1989;8(10):561-3.

21. Benson CB, Doubilet PM. Slow embryonic heart rate in early first trimester: indicator of poor pregnancy outcome. Radiology. 1994;192(2):343-4.

Cite this article as: Jaiswal J, Jaiswal AK, Patel G, Daharwal A. Effect of abnormal yolk sac, gestational sac and embryonic heart rate in pregnancy outcome. Int J Reprod Contracept Obstet Gynecol 2021;10:2993-8. 